\title{
Teo-Estetika-Filosofis Topeng Sidakarya Dalam Praktik Keberagamaan Hindu Di Bali
}

\author{
Komang Indra Wirawan
}

Pendidikan Seni drama tari dan musik

Universitas PGRI Mahadewa Indonesia

indrawirawan84@gmail.com

Topeng Sidakarya memeliki peranan penting dalam setiap upacara yadnya bagi umat Hindu di Bali. Upacara yadnya belum dinyatakan selesai sebelum dipentaskannya tarian sakral ini, sehingga dalam setiap prosesi ada pementasan tarian yang tergolong tari wali. Jenis tarian ini adalah bergenre tari topeng dengan atribut yang khas menampakan ketuaanya. Sidakarya secara literal berarti pekerajaan yang sudah tuntas atau selesai. Melalui pementasan tarian ini, masyarakat Hindu yang melangsungkan upacara yadnya diyakini sudah selesai menjalankan yadnya, dan tentunya ada pemberkatan di dalamnya. Tarian sakral yang menunjukan kesan magis, dan tidak saja dipandang sebagai pelengkap ritus yadnya, tetapi juga kaya makna teologi, keindahan dan filosofis yang berhubungan dengan praktik beragama Hindu di Bali yang di dalamnya tidak terlepas dari konsep satyam, siwam dan sundaram.

Kata kunci: topeng sidakarya, teologi-estetika-filsafat

\section{Theo-Aesthetic-Philosophy Of Sidakarya Mask In Hindu Religious Practice In Bali}

Sidakarya's mask has an important role in every yadnya ceremony for Hindus in Bali. Yadnya ceremony has not been declared finished before the performance of this sacred dance, so that in every procession there is a dance performance that is classified as guardian dance. This type of dance is a mask dance genre with distinctive attributes displaying its leader. Sidakarya literally means a completed or finished work. Through this dance performance, Hindus who hold their yad ceremony are believed to have finished their yad, and of course there are blessings in it. Sacred dance that shows a magical impression, and is not only seen as a complement to the rites of yadnya, but also rich in theological, beauty and philosophical meaning associated with Hindu religious practices in Bali which in it is inseparable from the concept of satyam, siwam and sundaram.

Keywords: sidakarya mask, theology-aesthetics-philosophy

Proses Review : 1 - 20 Mei 2021, Dinyatakan Lolos: 31 Mei 2021 


\section{PENDAHULUAN}

Kesenian di Bali bersumber pada Agama Hindu yang dilestarikan oleh adat setempat, sehingga merupakan wujud bakti kepada Tuhan Yang Maha Esa yang pada setiap pementasannya mengandung ajaran-ajaran agama. (Rianta, I. M., Santosa, H., \& Sariada, I. K. ,2019)

Terdapat beragam rupa aktivitas budaya yang menyatu dengan berbagai sendi kehidupan dalam lingkungan sosial masyarakat Hindu di Bali. Aktivitas budaya tersebut merupakan ekspresi jiwa sebagai bentuk responnya terhadap alam lingkungan tempat hidupnya maupun sebagai bentuk respon terhadap pengalaman hidupnya. Oleh sebab itu, di setiap daerah memiliki kekhasan budaya sesuai dengan potensi alam maupun potensi SDM (baca: Sumber Daya Manusia) masing-masing daerah bersangkutan. Dari berbagai rupa aktivitas budaya masyarakat Hindu di Bali tersebut, salah satu di antaranya adalah aktivitas berkesenian (sakral-nonsakral) yang terdiri dari seni tari, seni rupa, seni lukis, seni suara, seni musik, seni sastra, dan sebagainya(Indra Wirawan, K. 2019)

Topeng adalah benda yang dipakai di atas wajah. Biasanya topeng dipakai untuk mengiringi musikkesenian daerah. Topeng sebagai kesenian daerah pada umumnya dipakai untuk menghormati sesembahan atau memperjelas watak dalam mengiringi kesenian. Bentuk topeng tersebut ada bermacam-macam, ada yang menggambarkan watak marah, ada yang menggambarkan lembut, dan ada pula yang menggambarkan sifat-sifat kebijaksanaan (Suhardhana, 2010: 32).Topeng merupakan salah satu bentuk ekspresi paling tua dalam kesenian daerah yang pernah diciptakan peradaban manusia. Dalam kehidupan berkesenian pada sebagian besar masyarakat dunia, topeng memegang peranan yang sangat penting dalam berbagai sisi kehidupan yang menyimpan nilai-nilai magis dan suci. Hal ini disebabkan karena topeng yang besar peranannya sebagai simbol-simbol khusus dalam berbagai uparaca dan kegiatan adat yang luhur.

Pada kehidupan masyarakat modern saat ini topeng ditempatkan sebagai salah satu bentuk karya seni tinggi. Tidak hanya karena keindahan estetis yang dimilikinya, tetapi sisi misteri yang tersimpan pada raut wajah topeng tersebut tetap mampu memancarkan kekuatan magis yang sulit dijelaskan.Di Indonesia topeng telah ada sejak zaman prasejarah. Secara umum penggunaan tari topeng digunakan dalam berbagai upacara adat dan agama atau penceritaan kembali cerita-cerita kuno dari para leluhur. Diyakini bahwa topeng berkaitan erat dengan roh-roh leluhur yang dianggap sebagai interpretasi dewa-dewa. Pada beberapa suku, topeng masih menghiasi berbagai kegiatan seni dan adat sehari-hari. Beberapa topeng di Indonesia pun digunakan sebagai hiasan di dalam rumah atau di luar rumah. Beberapa kesenian topeng Indonesia antara lain: Tari Hudog suku Dayak, tari Topeng Bali, dan tari topeng Cirebonan (Dibia, 2014: 21).

Fungsi topeng dan pertunjukan topeng adalah untuk pemenuhan kebutuhan ekspresi seni, banyak seniman atau kriyawan pada era sekarang membuat topeng bukan dilandasi unsur religi, penciptaan topeng merupakan upaya untuk menggmbarkan tipologi perwatakan tokoh tertentu. Dalam tata kehiduan modern sekarang ini, peran topeng terjadi pergeseran dan perkembangan bentuk baik yang menyangkut corak, ukuran, gaya, maupun fungsinya. Oleh karena itu, dalam penciptaan topeng tidak hanya terbatas bentuk tradisional (klasik) saja, melainkan juga pengembangan variasi bentuk dan fungsi sebagai kreasi baru.(Martono, M., Iswahyudi, I., \& Handoko, A.2017)

Tari topeng di Bali merupakan sebuah dramatari yang semua penarinya memakai topeng atau tapel. Ada dua jenis pertunjukan tari topeng, yaitu : yaitu Topeng Pajegandan topeng Panca. Topeng Pajeganini terkenal dengan nama topeng Sidakarya karena merupakan sarana dari upacara Dewa Yadnya. Waktu pementasan tari topeng Sidakarya ini bersamaan dengan puncak pelaksanan upacara. Topeng Pajeganini dipentaskan oleh seorang penari dengan menokohkan kurang lebih 15 (lima belas) buah topeng (I Made Bandem, Ensiklopedia Tari Bali, Akademika Seni tari Indonesia, 1983,P. 140). Diantara ke lima belas topeng tersebut, topeng Sidakarya dianggap topeng yang paling penting, karena topeng Sidakarya merupakan simbol dari turunnya Wisnu Murti (Tuhan) untuk menyelesaikan upacara tersebut.

Topeng Sidakarya ini tergolong kedala tari wali, yang mana tempat pementasannya selalu dekat dengan pelaksanaan upacara tersebut. Tarian ini berfungsi untuk sarana upacara, yang dipentaskan bersamaan dengan Ida Pedanda mapuja. Topeng ini tampil sebagai pamungkas tari persembahan sebelum acara pemujaan bersama yang dipimpin oleh Sulinggih dilakukan. Berkenaan atas hal tersebut, tentu ada beragam makna teologi, estetika dan filsafat yang ada pada tarian sakral tersebut, dan hal tersebut dimunculkan dalam kajian ini.

\section{Kajian Pustaka}

Ada beberapa kajian pustaka yang digunakan dalam kajian ini yang tentunya memiliki relevansi dengan kajian, yakni: 1) Eka Santhosa (2019) The Scret Massage Dalem Sidakarya yang menjelaskan tentang kerahasiaan dibalik sosok dalem Sidakarya, 2) Suhardana (2010) Dalem Sidakarya Brahmana Sakti dari Keling yang menjelaskan sejarah dari kedatangan Brahmana Keling ketika sedang ada prosesi yadnya pada masa era Dalem Watrenggong di Gelgel, 3) Dibia (2017) dalam buku Geliat Seni Pertunjukan di Bali yang menjelaskan estetika pementasan seni pertunjukan di Bali, baik wali, bebali dan balih-balihan. 


\section{Teori Religi}

Emosi keagamaan mendorong orang melakukan tindakantindakan yang bersifat religi. Diantara memberikan suatu nilai religi yang lebih terhadap benda yang mempunyai nilai keramat (Koentjaraningrat,1997:210). Menurut E. Durkheim dalam Koentjaraningrat (1997: 201-202) menyatakan bahwa terdapat lima unsur religi adalah sebagai berikut.

1. Emosi keagamaan (getaran jiwa) yang menyebabkan bahwa manusia didorong untuk berperilaku keagamaan.

2. Sistem kepercayaan atau bayang-bayang manusia tentang bentuk dunia, alam, alam gaib, hidup, maut dan sebagainya.

3. Sistem ritus dan upacara keagamaan yang bertujuan mencari hubungan dengan dunia gaib berdasarkan sistem kepercayaan.

4. Kelompok keagamaan atau kesatuan-kesatuan sosial yang mengkonsepsikan dan mengaktifkan religi berikut sistem upacara-upacara keagamannya.

5. Alat-alat fisik yang digunakan dalam ritus dan upacara keagamaan.

\section{Teori Estetika}

Seni tidak selau indah menyenangkan ideal keindahan dapat bervariasi dan sangat tergantung kepada ideal dari tata nilai kehidupan. Keindahan adalah nilai (value) yang dibentuk citarasa perasaan manusia yang bersifat subyektif, sebagai tanggapan emosional terhadap kualitas bentuk suatu karya. Adanya dua konsep yang saling berlawanan (obyektif-subyektif) yang saling berlawanan itu melahirkan konsep lain yang bersifat kompromi. Estetika yang dilihat sebagai filsafat seni, maka peranan keindahan boleh dianggap esensial, namun tidaklah sebesar yang dibayangkan, walaupun sebutan estetika memberikan kesan sebaliknya (Sachari,2002:99). Djelantik (1992:2) menyebutkan bahwa apa yang disebut indah dapat menimbulkan dalam jiwa rasa senang, rasa bahagia, rasa tenang nyaman, dan bila kesannya lebih kuat, membuat seseorang menjadi terpaku, terharu, dan timbul keinginan untuk kembali menikmatinya (dalam bahasa Bali disebut kelangen). Berdasarkan hal tersebut, estetika atau keindahan merupakan seni identik dengan keindahan yang membuat jiwa seseorang menjadi kelangen, dan ada rasa untuk menikmati kembali rasa keindahan tersebut. Dengan demikian dapat dikemukakan bahwa karya seni secara implisit merupakan media untuk seseorang memasuki dimensi rohani. Teori tersebut digunakan untuk menelaah terkait keindahan dalam aspek Nataraja dalam hubungannya dengan tari Bali.

\section{METODE PENELITIAN}

Pendekatan yang digunakan dalam penelitian ini adalah pendekatan teo-estetika Hindu.Sumber data dalam penelitian ini menggunakan sumber primer dan skunder. Selanjutnya teknik pengumpulan data dalam penelitian ini menggunakan beberapa teknik, yakni: 1) observasi partisipan, yakni peneliti terlibat dalam penelitian dan kajian, 2) wawancara yang digunakan adalah wawancara tidak tersutruktur atau wawancara mendalam, 3) pengumpulan data melalui studi dokumen, yaitu mengumpulkan data-data yang terkait dengan peneltian, baik dari jurnal, buku, koran dan sejenisnya.

\section{Hasil Kajian}

\section{Teo-Estetika Tari Topeng Sidakarya}

Konsep adalah idea atau pengertian yang diabstraksikan dari peristiwa konkret, gambaran mental dari obyek atau apapun yang ada diluar bahasa digunakan oleh akal budi untuk memahami hal-hal-hal lain. Konsep ada karena adanya seniman yang menghadirkan karya seni . Penghadiran karya seni ini dapat disebut sebagai reprensentasi dari kebenaran atau kenyataan semesta sebagaimana ditemukan oleh senimannya. Gambaran yang dapat dipresentasikan dari pertunjukan tari Topeng Sidakarya meliputi 3 (tiga) konsep, yaitu :

\section{Konsep keindahan}

Konsep keindahan merupakan hal yang sangat penting diperhatikan dalam berkesenian. Pada umumnya keindahan itu dapat menimbulkan dalam jiwa rasa senang, bahagia, rasa tenang, nyaman dan lain sebagainya. Keindahan itu dapat dikatagorikan menjadi 2 (dua), yaitu keindahan alam, dan keindahan yang dibuat oleh manusia atau yang sering disebut kesenian. Keindahan dalam hal ini adalah sesuatu yang dapat menyenangkan dan dapat memenuhi keinginan terakhir ini, Tari Topeng Sidakarya mengandung makna pencapaian keindahan yang terkait dengan Ketuhanan. Konsep Ketuhanan dalam keindahan yang dimaksud dalam Topeng Sidakarya adalah suatu konsep yang lebih mengutamakan moral dan konsentrasi penari pada tatanan ritual, sehingga dapat mencapai keindahan bersatunya antara manusia dengan Tuhan.

\section{Konsep nilai ritual}

Konsep ini berkaitan dengan upacara keagamaan, atau tata cara yang terdapat dalam pelaksanaan upacara agama, yang hadir berupa kesenian untuk memperkuat kepercayaan, serta memformulasikan konsepsi agama dalam kehidupan. Kasenian merupakan salah satu cara yang tergolong "bakti marga dan karma marga " yang bertujuan untuk mencapai kesatuan dengan Tuhan Yang Maha Esa. Getaran rasa cinta dapat mendorong manusia untuk berbuat dan dapat melahirkan keikhlasan untuk berkorban. Mereka ingin mempersembahkan segala sesuatu yang terbaik untuk Tuhan. Ritual merupakan suatu bentuk upacara yang berhubungan dengan beberapa kepercayaan atau agama dengan rasa tulus ikhlas dan dapat menimbulkan rasa hormat yang luhur.

\section{Konsep nilai spiritual}

Nilai spiritual menyangkut masalah bathin dan watak. 
Hidup dalam aktivitas jiwa manusia., seperti rasa nikmat dan indah, karena terjadi kesan dalam jiwa melalui salah satu dari panca indria mata atau telinga atau keduanya sekaligus. Nilai spiritual adalah nilai sifat dan mutu dari pengalaman indah dalam kejiwaan, yang menyangkut masalah hasil obyektif moral. Spiritual memerlukan konsentrasi jiwa dan raga yang mengutamakan bathin dan kerohanian terpusat secara vertikal. Nilai-nilai inilah yang perlu diperdalam oleh seorang penari Topeng Sidakarya, karena konteknya terhadap upacara sangat intens. Nilai spiritual ini dapat memberikan motivasi untuk tercapainya kesucian jiwa.

\section{Arti Kata Topeng}

Sebelum menjelaskan sejarah topeng Dalem Sidakarya, menjadi hal yang penting untuk dipahami mengenai arti topeng. Topeng memiliki beberapa pengertian, yakni topeng merupakan suatu benda penutup muka. Disini yang dimaksud "tutup" tentunya adalah tutup untuk menutupi wajah manusia. Zoete dan Walter Spies dalam bukunya berjudul Dance adan Drama in Bali, menjelaskan “...,for topeng simply means somthing pressed a gainst the face, is a mask,...."artainya: “...,topeng secara sederhana suatu benda yang ditekankan pada muka, yaitu tapel,....". Demikian pula ada mengartikan, bahwa topeng berasal dari kata "tup" yang berarti tutup. Kata "tup" mengalami gejala bahasa sehingga ditambahkan "eng" yang kemudian menjadi tupeng. Bagi masyarakat Bali sendiri, memang kata topeng berarti tutup muka, sehingga tari topeng dikatakan sebagai tari dimana penari memakai tutup muka (topeng). Beragam varian tapel digunakan, seperti tapel Dewa, binatang, manusia, raksasa dan varian lainnya.

\section{Sejarah Topeng}

Sejarah topeng di Bali dapat dikatakan masih samarsamar. Mereka para seniman topeng dan penari juga tidak banyak mengetahui tentang sejarah topeng. Hal tersebut dikarenakan sulitnya menjelaskan keberadaan seni topeng di Bali berdasarkan data-data, baik berupa prasasti maupun lontar-lontar yang menjelaskan tentang kesenian topeng. Di daerah Jawa Tengah ada prasasti Jaha (840 Masehi) yang memuat tentang seni pertunjukan topeng. Prasasti tersebut dikeluarkan oleh Sri Lokapala penguasa daerah Kuti, dan dalam prasasti tersebut disebutkan beberapa seni pertunjukan:

1. Juru Jalir, berarti petugas yang mengatur pertunjukan,

2. Dagang, berarti petugas yang mengurus tentang badut,

3. Atapukan, berarti seni pertunjukan topeng,

4. Arinngit, berarti seni pertunjukan wayang,

5. Abanwan, berararti lelucon,

6. Haluwarak, yakni keluarga bangsawan yang memimpin seni pertunjukan wayang dan topeng,

7. Winingle, berarti penabuh,

8. Pawindu, berarti dalang atau penari yang memakai wawankata.

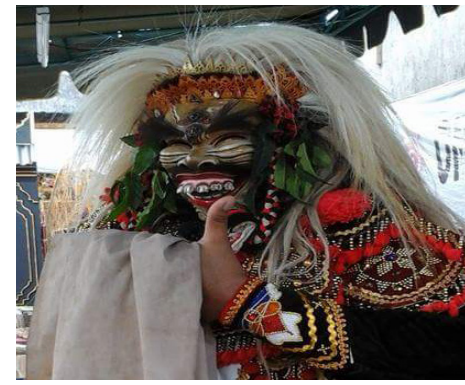

Gambar 1 gambar topeng sidekarya (Sumber:gases bali,2019.)

Berdasarkan uraian tersebut, maka sangat jelas bahwa kata “Atapukan” berarti seni pertunjukan topeng. Selain prasasti tersebut, diketemukan pula prasasti lain yang menjelaskan tentang seni pertunjukan topeng, yaitu Prasasti Balitung (907 Masehi). Bunyi prasasti tersebut: “...,Sanghyang Tangkil Hyang (mamidu), si Nalu macarita (bercerita) Bhima Kumara. Mangigel (menari) sabagai kecaka sa jaluk macarita Ramayana (bercerita Ramayana), si mung muk mamirus (berekting) dan mebanol (berlelucon), si Galigi mawayang (mempertunjukan wayang) untuk para leluhur, dengan ceritra Maya Kumara. Para bangsawan bersiap bermain judi, sementara itu dua orang bersiap memakai pakaian Atapukan atau topeng."

Sedangkan di Bali diketemukan prasasti yang menyebutkan seni pertunjukan topeng, yakni prasasti Bebetin. Dalam prasasti tersebut disebutkan kata "Partapukan" yang berarti topeng atau tapel. Disamping prasasti tersebut, selanjutnya ditemukan sebuah Lontar yang menjelaskan tentang seni pertunjukan Topeng, yakni Lontar Ularan Prasraya. Lontar tersebut mengisahkan pemerintahan Dalem Waturenggong (1460-1550) di Gelgel. Diceritakan pada masa pemerintahannya, beliau berkenhendak menaklukan Blambangan. Dikirimlah pasukan dibawah pimpinan Ki Pataih Ularan dan ditemani oleh Ki Gusti elantik Pesimpangan. Pada saat penyerbuan tersebut, Sri dalem Juru dapat dipenggal kepalanya dan Balambangan dapat ditaklukan. Pada saat terjadi perampasan, berbagai barang dirampas sebagai bukti penaklukan. Diantara benda-benda tersebut, ada satu peti topeng serta satu keropak wayang Gambuh. Dapat diperkirakan keberadaan seni pertunjukan topeng di Bali sudah ada sebelum masa Pra Gelgel, dan duteruskan kembali pada masa Gelgel dan raja berikutnya.

\section{Makna Filosofis Topeng Dalem Sidakarya}

Dalam pementasannya, hal yang sangat pokok dapat dikenali dari pementasan tari Topeng Sidakarya adalah bentuk topeng yang khas dan memiliki karakterisitik unik. Tipe topeng Dalem Sidakarya dapat dilihat pada gambar 1.

1. Topeng berwarna putih, yakni simbol kesucian. Hal tersebut mencirikan bahwa Dalem Sidakarya merupakan orang yang memiliki kesucian. Dalam Tattwa Siwa Siddhanta, warna putih berada di timur, dewanya Iswara bersenjatakan Bajra/Genta merupakan simbol kependetaan dan kebrahmanaan. 
Seorang dikatakan Brahmana sudah tentu memiliki tingkat kesucian yang tinggi, dan menguasai ilmu pengetahuan Weda.

2. Mata topeng sipit, yakni simbol mawas diri dan selalu memperhatikan segala kondisi baik eksternal dan internal. Mata sipit sebagai simbol dari tapa, yakni mata setengah terbuka dan terpejam. Dalam yoga, posisi mata yang demikian merupakan lambang dari pengendalian indria dan pemusatan pikiran pada satu titik pusat.

3. Gigi jongos, memang secara harfiah kelihatannya gigi jongos akan mengurangi ketampatan seseorang. Namun dalam tipe pakem topeng Sidakarya justru keunikannya terletak pada tipe giginya yang jongos. Bahkan ada kayakinan, kekuatan atau taksu dari topeng Sidakarya terletak pada giginya. Gigi jongos sesungguhnya adalah simbol dari kesederhanaan, dan lambang kekuatan sebagai penyeimbang. Gigi yang demikian sangat dekat disimbolkan dengan Tantrik, yang bermakna kekuatan penyeimbang.

4. Wajah setengah manusia dan setengah demanik, merupakan simbol keseimbangan. Wajah manusia dan demanik merupakan konsep Rwa Bhineda yang mutlak ada dalam diri dan dalam alam makro. Dua karakter tersebut harus diseimbangkan, dalam artian leburlah sifat demanik (keraksasaan) kedalam sifat dewa sehingga menjadi manusia yang dewata.

5. Rambut panjang sebahu, dapat dimaknai sebagai lambang ketidak terikatan dan warna putih rambut simbol dari kebrahmanaan yang menjungjung ajaran kesucian.

6. Memakai kain krudung merajah sebagai simbol dari Tri Kona, lahir, hidup dan kematian sebagai lingkaran yang tidak pernah putus. Tiga hal tersebut ada dalam yadnya, dan Dalem Sidakaryalah yang berfungsi untuk melebur segala prosesi yadnya sehingga semua berakhir dengan iklas dan tiada keterikatan akan apa yang dipersembahkan.

7. Penari biasanya membawa bokoran berisi canang sari, dupa, beras kuning, sekar ura, sebagai simbol kedermawanan dan penuh dengan berkah serta karunia. Apa yang dibawakan akan membawa pada kemakmuran dan kesejahteraan bersama (Lokasamgraha).

\section{Busana Topeng Dalem Sidakarya}

1. Baju Bluduru difungsikan untuk menutup badan/ tubuh penari simbol dari kesopanan dan pengendalian indria.

2. Kamen Putih Lelancingan difungsikan untuk menutup bagian bawah tubuh, warna putih simbol kesucian, dan lelancingan adalah simbol kepurusan (maskulin).

3. Celana Panjang Putih difungsikan untuk menutup bagian kaki, simbol kesopatan dan kemana kaki sang Brahmana melangkah diikuti oleh kesucian itu sendiri.

4. Badong difungsikan untuk menutup leher sampai dada

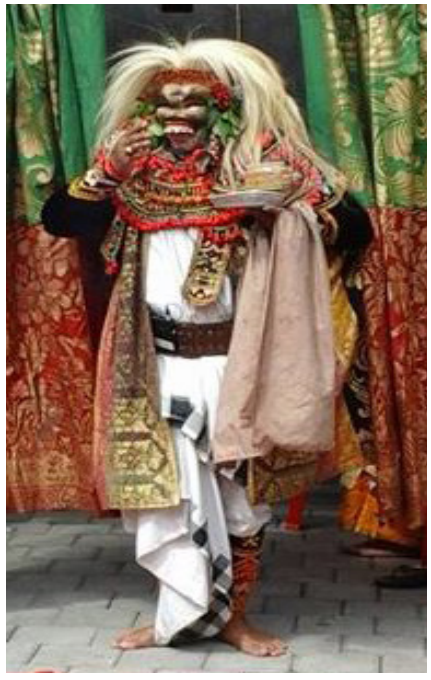

Gambar 2. gambar topeng sidekarya (Sumber:Gases Bali,2019)

penari, simbol dari penguasaan ilmu pengetahuan.

5. Angkep Pala digunakan untuk menutupi pala/bahu, simbol dari kegagahan dan kemuliaan.

6. Saput Petopengan digunakan untuk menutup badan penari topeng, simbol dari pengendalian diri, kesederhanaan dan selalu melihat ke dalam diri.

7. Angkep Tundu difungsikan untuk menutupi punggung penari, simbol dari sudah tunduknya rasa ego dan tidak lagi membicarakan keburukan orang dari belakang.

8. Gelang Kana difungsikan dan ditempatkan pada kedua tangan penari, simbol kedermawanan.

9. Gelang Batis difungsikan dan diletakan pada pergelangan kaki, simbol dari kehati-hatian dalam melangkah, dan kemana sang Brahmana melangkah selalu mendatangkan kemuliaan.

10. Sabuk difungsikan untuk mengikat pinggang, simbol kerendahan hati, dan pengendalian indria.

11. Keris ditempatkan dipunggung penari, dan keris memiliki beragam makna sebagai simbol Sanghyang Rwa Bhineda, dan ketajaman intelek/budhi.

12. Gelungan Sesobratana, diletakan di kepala, simbol kemuliaan dan kesederhanaan.

13. Daun Girang, Bulu Merak difungsikan sebagai hiasan telinga penari, simbol keriangan dan bulu merak simbol kemuliaan demikian juga Dalem Sidakarya sudah mampu menundukan kecongkakaknnya.

14. Benang Tridatu,simbol Sanghgyang Tripurusa, dan menyucikan ketiga alam, alam bawah, tengan dan atas.

Makna Posisi Gerak Tangan (Mudra) Topeng Sidakarya Setiap tarian sakral di Bali tidak dapat dipisahkan dari konsep Yantra, Tantra dan Mudra. Khususnya gerakan tarian topeng Sidakarya yeng di dalamnya ada simbol mudra yang dalam akan makna. Sebelum lebih jauh kita memaknai postur tangan tari topeng Sidakarya yang tiada lain adalah Mudra, maka terlebih dahulu kita akan menjelaskan sekilas tentang Mudra. Mudra Wignana adalah ilmu pengetahuan tentang Mudra adalah rahasia 
tubuh manusia yang sangat luar biasa hebatnya. Kekuatan tersebut kita sangat jarang mengetahuinya, bahkan para pelaku seni topeng pun tidak banyak mengetahui rahasia dari gerakan tangan (Mudra). Menurut penelitian praktisi Tantra, berbagai jenis gelombang elektrik dalam tubuh mengalir ke jari-jari. Menggerakan jari-jari dengan postur Mudra akan membangunkan sel-sel syaraf kecil yang tertidur sehingga kesehatan menjadi prima. Dalam Tantra Sastra, dijelaskan bagaimana Mudra bekerja. Pada saat menggerakan posisi tangan (Mudra) energi sakti bergerak ke ujung jari, dan dari ujung jari mengeliuarkan vibrasi yang kuat sehingga dapat menyalurkan kekuatan suci atau energi saktipat.

Mudra merupakan ilmu pengetahuan Yoga, membangunkan energi kosmis untuk membersihkan tubuh, pikiran, dan jiwa. Mudra secara tidak langsung dapat dijadikan media penyembuhan, baik sakit fisik dan mental. Lalu, bagaimana Mudra dapat membangkitkan energi alam/kosmis? Seluruh alam dibentuk oleh lima unsur, yakni Perthiwi, Jala, Agni, Wayu, dan Akasa. Sesungguhnya seluruh jari tangan berhubungan dengan lima elemen tersebut, dan elemen tersebut secara gaib dapat menyembuhkan karena Mudra dapat membangkitkan energi Atom dalam tubuh. Adapun lima elemen yang terdapat dalam masing-masing jari-jari, yaitu:

1. Ibu Jari mewakili unsur akhasa atau angkasa,

2. Jari Telunjuk mewakili unsur wayu atau udara,

3. Jari Tengah mewakili unsur agni,

4. Jari Manis mewakili unsur perthiwi/bhumi,

5. Jari Kelingking mewakili unsur jala, waruna atau air.

Elemen tersebut akan bekerja dengan baik, jika masingmasing elemen tersebut bersatu, dan dalam Mudra meyatukan unsur tersebut dengan cara mengkaitkan jari satu dengan jari lainnya. Gerakan tangan, jari, kepala, mata dan anggota tubuh lainnya dapat menggerakan drama tanpa kata, mengekspresikan pengalaman manusia sehari-hari, serta kehidupan para dewa dan semesta. Terlebih gerakan postur jari dalam tarian topeng Sidakarya memiliki makna yang pararel dengan makna Mudra sebagai media membangun energi alam agar Bhuwana Alit dan Bhuwana Agung dapat tersucikan. Dengan demikian, adapaun gerakan postur jari/Mudra dan maknanya dapat dilihat sebagai berikut.

\section{Posisi Jari Ngaruji atau Abhaya Mudra}

Dalam tarian topeng Dalem Sidakarya, postur jari penari sering menunjukan posisi jari ngaruji. Postur jari ngaruji sama dengan postur jari dalam Mudra yang disebut Abhaya Mudra. Abhaya Mudra memeliki makna yang dalam, yakni perlindungan dan kebanyakan dari postur tangan Dewa-Dewi Hindu dalam posisi Abhaya Mudra sebagai yang memberikan perlindungan. Bahkan dalam Tantra Sastra posisi jari tangan yang demikian dapat dimaknai "kamu jangan takut Tuhan selalu bersamamu". Ngaruji ini sering ditunjukan oleh penari topeng Sidakarya sebagai simbol bahwa Ida Sanghyang Widhi dapat memberikan perlindungan, dan menghindarkan diri dari segala rintangan.

\section{Posisi Jari Nyigit atau Jñana Mudra}

Posisi jari nyigit sering ditunjukan oleh penari topeng dalem Sidakarya, dan dalam Tantra Sastra, khususnya Mudra posisi jari tersebut sama dengan postur jari Jñana Mudra. Mudra ini sangat penting dan Dewa-Dewa Hindu sering memperlihatkan posisi jari dengan posisi Jñana Mudra. Mudra ini adalah simbol dari kebijakasanaan,dan pertemuan ibu jari dengan jari telunjuk merupakan lambang penyatuan antara Paramatma sebagai kesadaran kosmis yang berada di Ibu Jari. Sedangkan di Jari Telunjuk simbol dari energi Jiwatman (kesadaran manusia). Bila kedua energi tersebut bertemu maka munculah kesadaran dalam diri. Posisi jari nyigit yang sering diperlihatkan dalam tarian topeng Dalem Sidakarya sebagai penanda bahwa untuk mencapai kesucian seseorang terlebih dahulu harus menyadari kesejatian diri, dan menunduk pada kesadaran tertinggi.

\section{Posisi Jari Ngawawaatau Siva Lingga Mudra}

Posisi jari Ngawawa sering diperlihatkan oleh penari topeng Sidakarya dan penari lainnya. Posisi jari Ngawawa dalam tarian memiliki kesamaan bentuk dan posisi jari dalam Mudra yang disebut dengan Siva Lingga Mudra. Siva Lingga Mudra sangat penting dalam Tantra Sastra, dan sering digunakan untuk penyembuhan melalui tubuh, bukan obat. Mudra ini dapat mengubah gerak enenrgi, melebur hambatan, dan hal negatif serta membangun kekuatan kehidupan yang positif. Penari topeng Dalem Sidakarya sering memperlihatkan posisi yang demikian sebagai simbol penetralisir kekuatan negatif menuju pada keseimbangan.

\section{Posisi Jari Nyitsit atau Chin Mudra}

Posisi jari nyitsit sering diperlihatkan oleh penari topeng Dalem Sidakrya maupun tarian lainnya. Posisi jari seperti ini hampir sama bentuknya dengan Chin Mudra dalam Tantra Sastra. Mudra demikian memiliki makna yang hampir sama pula dengan Jñana Mudra. Chin berasal dari istilah Chita dalam bahasa Sanskerta yang berarti pikiran. Mudra ini sering dimaknai sebagai pemunculan kesadaran pikiran.

\section{Posisi Jari Nyumput atau Samanahuti Mudra}

Posisi jari nyumput kadangkalanya diperlihatkan oleh penari topeng Dalem Sidakarya. Dalam pengetahuan Mudra posisi jari yang demikian disebut dengan Samanahuti Mudra yakni semua ujung jari-jari bertemu, dan Mudra ini simbol dari kesejahteraan serta kesehatan. Makna tersebut dilekatkan pada Mudra ini karena dalam Tantra posisi tangan yang demikian membantu asimilasi dalam tubuh sehingga kesehatan menjadi prima. Kesehatan merupakan lambang dari kesejahteraan. 


\section{Posisi Jari Manganjali atau Sangka Mudra}

Posisi jari manganjali dalam tarian, khususnya topeng dalem Sidakarya sering diperlihatkan pada awal tarian dan akhir pementasan atau pada momen lainnya. Posisi jari yang demikian, memiliki kesamaan dengan Sangka Mudra, yakni Mudra yang dimaknai oleh para Tantris sebagai simbol membuka pura dalam diri, dimana Tuhan bersthana di dalamnya. Dalam pementasan tari topeng Dalem Sidakrya, sikap tangan manganjali simbol dari penyucian diri dan penyucian di luar diri.

\section{Posisi Jari Nuding Duaatau Perthiwi Mudra}

Posisi jari nuding dua ini sangat sering diperlihatkan oleh penari, terlebih penari topeng Dalam Sidakarya. Dalam pengetahuan Mudra posisi jari yang demikian disebut dengan Perthiwi Mudra, dan Mudra tersebut sering digunakan oleh pengikut Tantra untuk membangkiktkan kekuatan cakra dalam tubuh. Perthiwi lambang bumi, dan bumi adalah ibu bagi manusia serta bumi adalah lambang kesuburan dan kemakmuran. Sejalan dengan itu, tarian topeng Dalem Sidakarya merupakan tarian simbol pemarisuda agar bumi menjadi makmur dan sejahtera. Demikian juga melalui yadnya, bumi akan memberikan kesuburan.

\section{Posisi Jari Ngeregep atau Dhyana Mudra}

Posisi tangan atau jari ngeregep sering diperlihatkan dalam pementasan tarian sakral Dalem Sidakarya. Ngeregep dalam Mudra hampir sama dengan posisi Dhyana Mudra. Dhyana Mudra sering digunakan dalam sadhaka melakukan meditasi, dan sang Bhuda sering menggunakan sikap ini dalam memusatkan pikiran. Dengan demikian, Mudra ini simbol dari pemikiran yang terpusat pada nafas (nyeraya) sehingga energi dapat difokuskan agar energi kosmik dapat mambantu kehidupan duniawi. Hal tersebut, sejalan dengan makna dari pementasan topeng Sidakarya sebagai pemarisudha agar yadnya sukses dan alam semesta tersucikan.

\section{Posisi Jari Ngebat atau Japa Mudra}

Posisi jari ngebat sering digunakan dalam pentas tarian, khususnya tari topeng Sidakarya. Dalam Mudra sikap jari yang demikian disebut dengan Japa Mudra yakni memiliki makna sebagai pemuasatan segala gerak indria pada satu objek. Japa ngaran mantra (japa artinya mantram), dan posisi jari ngebat dapat dimaknai sebagai simbol penyatuan kekuatan mantram yang diucapkan sebagai media untuk penyucian. Demikian juga japa dipersepsikan sama dengan jnana, dan melalui jnana seseorang dapat menyucikan dirinya. Adapaun

\section{SIMPULAN}

Kesenian di Bali bersumber pada Agama Hindu yang bersumber pada adat setempat, sehingga merupakan wujud bakti pada Tuhan Yang Maha Esa yang pada setiap pementasanya mengandung ajaran-ajaran agama, salah satunya seni topeng Sidekarya. Topeng Sidekarya memiliki peranan penting dalam setiap upacara yadya bagi umat Hindu di Bali. Upacara Yadya belum dinyatakan selesai sebelum di pentaskanya tarian Topeng Sidekarya. Sidekarya secara literal berarti pekerjaan yang sudah tuntas atau selesai, dalam pementasan tari Topeng Sidekarya memiliki 3 konsep yaitu: Konsep keindahan, Konsep nilai Ritual dan Konsep nilai Spiritual, di mana ketiga konsep itu memiliki sebuah makna penyatuan Sad Rasa, menjadi Sad Guna sehingga terbentuk Sadining Lango atau Kelangoan. Dalam Topeng Sidekarya banyak makna filosofis yang dapat kita jadikan sebuah refleksi cerminan seperti hal nya topeng berwarna putih sebagai simbul kesucian, Mata Sipit yakni simbul mawas diri, Gigi Jongos simbul dari kesederhanaan dan lambang kekuatan sebagai penyeimbang, wajah setengah manusia atau Demanik simbul keseimbangan atau Rwa Bhineda, rambut panjang dimaknai sebagai ketidak terikatan serta masi banyak lagi makna filosofi yang terdapat dalam Topeng Sidekarya termasuk gerak tangan atau Mudra yang dipergunakan saat pementasan berlangsung. Dapat disimpulkan bahwa tari Topeng Sidekarya sebagai simbul pemberi anugrah kesejahteraan, menghilangkan segala Papa klesa, dan penyakit dalam diri dan alam (Buana Alit dan Buana Agung).

\section{DAFTAR RUJUAN}

Bandem, I Made. 1983, Ensiklopedia Tari Bali, Akademika Seni tari Indonesia.

Indra Wirawan, K. (2019). Liturgi Sakralisasi BarongRangda: Eksplorasi Teo-Filosofis Estetik Mistik Bali. Mudra Jurnal Seni Budaya, 34(3), 417-427. https://doi. org/10.31091/mudra.v34i3.800

Martono, M., Iswahyudi, I., \& Handoko, A. (2017). Topeng Etnik Nusantara Dalam Perkembanagan Budaya Global. Mudra Jurnal Seni Budaya, 32(1). https://doi. org/10.31091/mudra.v32i1.91

Rianta, I. M., Santosa, H., \& Sariada, I. K. (2019). Estetika Gerak Tari Rejang Sakral Lanang Di Desa Mayong, Seririt, Buleleng, Bali. Mudra Jurnal Seni Budaya, 34(3), 285-393. https://doi.org/10.31091/mudra.v34i3.678

Suteja, I Ketut ,2005, Tari Sunya Transformasi konsep dan filosofi tari topeng Sidakarya Dalam Mudra Jurnal Seni Budaya Vol. 16, 1 Januari 2005.

Tim Penyusun Kamus Pusat Pembinaan dan Pengembangan Bahasa, 1990. Kamus Bahasa Indonesia, Departemen Penddikan dan Kebudayaan, Balai Pustaka, Jakarta.

Suhardana,Drs.K.M., 2006, Pengantar Etika dan Moralitas Hindu,Paramita, Surabaya.

Yayasan Sanatana Dharmasrama, 2003, Intisari Ajaran Agama Hindu, Paramita, Surabaya 